\title{
Experiential Learning to Teach User Experience in Higher Education in Past 20 Years: A Scoping Review
}

\author{
Jin Kang *, Noemi M. E. Roestel and Audrey Girouard \\ School of Information Technology, Carleton University, Ottawa, ON, Canada
}

Experiential learning is an effective method to teach User Experience (UX) to Human-Computer Interaction $(\mathrm{HCl})$ students. Despite its popularity, there seems to be no comprehensive overview on (1) the current use of experiential learning in UX education at universities and (2) student learning outcomes and benefits resulting from the use of experiential learning. Hence, we conducted a scoping review to provide such overview. We analyzed 45 articles published from 2000 to 2021 and we found 12 types of experiential learning employed by $\mathrm{HCl}$ educators: applied research project, industry/community research project, hands-on activity, role-play, interactive workshops, guest speakers, in-house work placement, internship, flipped classroom, field project, lab, and design hackathon, from most to least frequent. Twenty-six articles reported student learning outcomes and benefits: (1) enhanced UX technical knowledge, (2)

OPEN ACCESS

Edited by:

Gerrit C. Van Der Veer, University of Twente, Netherlands

Reviewed by:

Styliani Kleanthous, Open University of Cyprus, Cyprus

Sandra Sanchez-Gordon, Escuela Politécnica Nacional, Ecuador

*Correspondence: Jin Kang jin.kang@carleton.ca

Specialty section:

This article was submitted to Human-Media Interaction, a section of the journal

Frontiers in Computer Science

Received: 10 November 2021 Accepted: 26 January 2022 Published: 03 March 2022

Citation:

Kang J, Roestel NME and Girouard A (2022) Experiential Learning to Teach User Experience in Higher Education in Past 20 Years: A Scoping Review.

Front. Comput. Sci. 4:812907.

doi: 10.3389/fcomp.2022.812907 applied textbook knowledge into practice, (3) acquired soft skills, (4) student satisfaction, (5) increased awareness of user diversity, and (6) increased job marketability. Overall, we advance current $\mathrm{HCl}$ teaching practices by providing $\mathrm{HCl}$ educators with a list of experiential learning types that they can adopt in their classes to teach UX.

Keywords: user experience, higher education, experiential learning, human computer interaction, scoping review

\section{INTRODUCTION}

Human-Computer Interaction (HCI) students typically learn about user experience (UX) during their studies. The field of $\mathrm{HCI}$ focuses on the design, implementation, evaluation of interaction systems that support human activity (Hewett et al., 1992) and thus it trains students on a wide range of UX topics, from accessibility to user-centered design and software development. HCI students should be able to create systems that provide the best possible interaction for intended users (Hewett et al., 1992; ACM, 2020).

There is a growing interest among HCI educators to adopt experiential learning as a pedagogical approach. For instance, out of 16 papers submitted to the Teachable Moment track at EduCHI from 2019 to 2021, a symposium to discuss HCI education, 8 papers (50\%) have presented new class activities that involved experiential learning.

The shift in higher education toward experiential learning makes sense against empirical evidence that suggests its superiority in fostering academic and workforce skills (Hamer, 2000; Sánchez et al., 2019). The power of experiential learning to successfully prepare students to be work-ready cannot be overstated. Many HCI students pursue UX industry after graduation (Rosala and Krause, 2019; Girouard and Kang, 2021) and yet employers question whether new graduates of computing disciplines are work-ready (Brechner, 2003; Radermacher and Walia, 2013). Hence, adopting experiential learning as a pedagogical method is a must, not an option. 
To date, HCI educators' efforts to advance HCI pedagogy can be classified in two ways: what topics should be taught and how should HCI topics be taught. The former identifies new HCI topics and curriculum that should to be taught to students in response to rapid technology advancement (Churchill et al., 2013; Musabirov et al., 2019); the latter focuses on proposing a new way of teaching HCI topics by providing a case of their individual pedagogical approach (Talone et al., 2017; Roldan et al., 2020; Lallemand, 2021). Our current work falls under the latter but we take a different approach. We offer a comprehensive overview of the types of experiential learning that have been used to teach UX (vs. focusing on an individual pedagogical approach).

Specifically, we asked two research questions. RQ1: What types of experiential learning have been employed by HCI educators to teach UX? and RQ2: What student learning outcomes and benefits have been reported, if provided? To address these questions, we conducted a scoping review of published articles from 2000 to $2021(N=45)$. In our analysis, we found 12 types of experiential learning and we also identified five student learning outcomes and benefits among the articles that have evaluated the effectiveness of their pedagogical approach.

Our contributions, which center on advancing the current practices of teaching UX concepts, skills, and methods, are the following:

- We trigger a critical reflection on the appropriateness of the UX teaching practice for past 20 years, potentially identifying if new types of experiential learning should be adopted.

- We provide a list of experiential learning types that can be used to teach UX in higher education. This overview empowers HCI educators to design and adopt techniques that match their goals and constraints.

- We offer insights on UX learning assessment methods that have been employed by HCI educators. This information identifies if any improvements are needed with the current assessment practice.

In this paper, we define HCI expansively to encompass computing and related disciplines that specifically focus on understanding the impact of ubiquitous computing on individuals. These disciplines include computer science, information technology, design, and psychology (Hewett et al., 1992).

\section{Benefits and Types of Experiential Learning}

Drawing from Kolb (1984), there are four major principles in experiential learning:

- Expose students to new experience. These experiences can be any hands-on activity to new information.

- Guide students to reflect on new experience. This guided reflection helps students to connect new experience to prior understanding.

- Encourage students to abstract new knowledge from reflection.

- Help students apply the new knowledge with a new practice set.
There are many types of experiential learning (hereafter, EL types). Most popular EL types are case study, work placement, lab, and role-play (Gittings et al., 2020). Benefits of experiential learning are well-documented and these benefits include increased technical knowledge and higher comprehension of a course content, higher student satisfaction and obtainment of employment at graduation (Gittings et al., 2020).

The hands-on aspect underlies all EL types and thus students can develop the same skills from participating in any of the EL types. But they may develop those skills at a greater depth from participating in more immersive EL types than less immersive EL types. This is because immersive EL types place students in touch with the real world and certain skills such as leadership and teamwork are learned better in a working situation than in class (Barr and McNeilly, 2002).

\section{Experiential Learning to Teach UX in $\mathrm{HCl}$}

In this paper, we define UX to refer to all aspects of a person's experience-emotion, behavior, and cognition-while interacting with computing systems (Hassenzahl and Tractinsky, 2006). HCI students master several competencies to achieve a high quality UX of a given computing system; these competencies center on HCI foundation (e.g., accessibility, user-centered design, human-centered software development), user testing (e.g., prototyping, evaluation techniques), statistical methods, and content strategy (Hewett et al., 1992; ACM, 2020).

HCI students have a great interest in pursuing UX careers (Yargin et al., 2018; Rosala and Krause, 2019). Yet, they feel and are ill-equipped to pursue UX careers (Gonzalez et al., 2014). Feeling and being unprepared for the UX industry can explain the surging adoption of experiential learning in HCI education since experiential learning can teach students professional skills (Talone et al., 2017).

Also, CS undergraduate students perceive $\mathrm{HCI}$ as too easy and common-sense (Edwards et al., 2006), which may contribute to their reluctance to adopt a user-centered approach in software development. Experiential learning can engage students and thus it is paramount to understand what EL types are available to HCI educators, so that they can adopt and use the technique in their UX teaching.

To date, there seems to be no comprehensive overview that shows different EL types employed by HCI educators to teach UX. A review-be it scoping or systematic-of experiential learning is done to improve curriculum and class delivery and ultimately the effectiveness of teaching (Gittings et al., 2020). We sought out to conduct a scoping review to assess and organize the available body of literature on UX education (Arksey and O'Malley, 2005). We posed the following research questions:

- Research Question 1 (RQ1): What types of experiential learning have been employed by HCI educators to teach UX in higher education?

- Research Question 2 (RQ2): What student learning outcomes and benefits have been reported? 
TABLE 1 | Key terms and their alternative terms.

\begin{tabular}{|c|c|c|}
\hline "Experiential learning" & "User experience" & "Higher education" \\
\hline $\begin{array}{l}\text { "active learning", } \\
\text { "student-centered learning", } \\
\text { "learning by doing", } \\
\text { "cooperative learning", } \\
\text { "problem-based learning", } \\
\text { Kolb^ }\end{array}$ & $\begin{array}{l}\text { UX*, usability, user*, } \\
\text { "accessibility", "web } \\
\text { analytics", "user research", } \\
\text { "interaction design", "visual } \\
\text { design", "content strategy", } \\
\text { "information architecture", } \\
\text { HCI, "human-computer } \\
\text { interaction" }\end{array}$ & $\begin{array}{l}\text { "tertiary } \\
\text { education", } \\
\text { universit* }\end{array}$ \\
\hline
\end{tabular}

\section{METHODS}

We followed PRISMA's guideline for a scoping review (PRISMA, 2021). The first and second authors conducted the review. We used a web-based review tool called Covidence to facilitate the process of initial paper screening [Veritas Health Information, (2014)] and Excel for final paper screening process.

\section{Database Selection}

Given the interdisciplinary nature of $\mathrm{HCI}$, we employed both computing-specific and non-computing-specific databases to capture as many relevant papers as possible. We used two databases-IEEE Xplore and ACM Digital Library-that specifically support computing research and another databaseScopus-that supports multidisciplinary research.

\section{Search String Development}

Our search string consisted of the three main key terms (i.e., experiential learning, user experience, and higher education) and their corresponding alternative terms (Table $\mathbf{1}$; for each column, the first row presents the key term). These key terms were determined based on our RQs and prior work on experiential learning (Gittings et al., 2020). For the term "user experience," we developed alternative terms based on seven knowledge branches of UX: information architecture, visual design, interaction design, user research, accessibility, content strategy, and web analytics [usability.gov, (n.d.); Tiwalolu, 2018]. We used the Boolean operator AND to separate the terms in each column; we used OR to connect alternative terms; we used an asterisk $\left(^{*}\right)$ to search for variations of word stems; we used a quotation ("') to get an exact match of that term. We searched for terms in title, abstracts, and keywords.

\section{Inclusion/Exclusion Criteria}

We only included articles that met all the following criteria:

1. The article must be published between 2000 and 2021. We chose this publication range because we see an upsurge of academic work on UX being published from 2000 (Lallemand et al., 2015).

2. The article must describe a pedagogical approach (e.g., course, workshop) that teaches skills and knowledge that fall within the seven UX branches defined above.

3. The article must address a pedagogical approach dedicated to undergraduate or graduate students in university.
4. The article must be peer-reviewed. It can be published in a journal or peer-reviewed proceedings of a conference. For conference proceedings, the article can be in any forms, including Gray literature (e.g., work-in-progress papers, extended abstracts). Gray literature is scholarly work that falls outside of typical peer-reviewed, full research articles [New York Academy of Medicine, 2009]. There is lack of research on experiential learning in HCI (Lee et al., 2019; Lima et al., 2021). By extending our search to include Gray literature, we are covering large and diverse sources of evidence, with the goal of providing a comprehensive overview on UX pedagogy. This inclusion practice of Gray literature aligns with recommended scoping review guidelines (Scherer and Saldanha, 2019; Sucharew and Macaluso, 2019).

5. The article must be a full text. Its entire textual content should be available in the database.

6. The article must be written in English.

\section{Additional Search for Articles}

We searched for additional articles by doing backward reference list checking. We examined references in the articles that we have already found from three databases. We also checked for relevant articles by using the "cited by" function in Google scholar. Lastly, we checked for articles available articles in EduCHI website; this symposium has specific paper track dedicated for sharing new HCI pedagogical approaches. The whole search was conducted for 1 week in July 2021.

\section{Article Screening Results}

We found a total of 1,128 articles from three databases and manual search process (Figure 1). We uploaded the full text of these papers on Covidence. Then the first and second authors reviewed each article on Covidence. Each of us marked the paper with Yes, Maybe, or No based on the following decision criteria:

- Yes: the title, abstract, and/or keywords refer to the three main key search terms (i.e., experiential learning, user experience, and higher education).

- Maybe: the title, abstract, and/or keywords refer to two of the three main key search terms.

- No: not the title and/or abstract may include a reference to one of the main key search terms, but the terms have no relationship with one another.

In this initial screening, we disagreed on 236 papers and the disagreement mainly arose because a paper's abstract, title, and/or keywords did not give clear indication of which UX knowledge and skills were being addressed. The discrepancy was resolved through discussion and reading the full text of a paper.

After resolving the disagreement, we had a total of 226 papers that were eligible for final paper screening process. In this final screening process, each reviewer independently checked the article against the inclusion criteria. We coded the article as the following:

- Yes, in which the paper satisfies all the criteria.

- No, in which the paper satisfies all the criteria. 


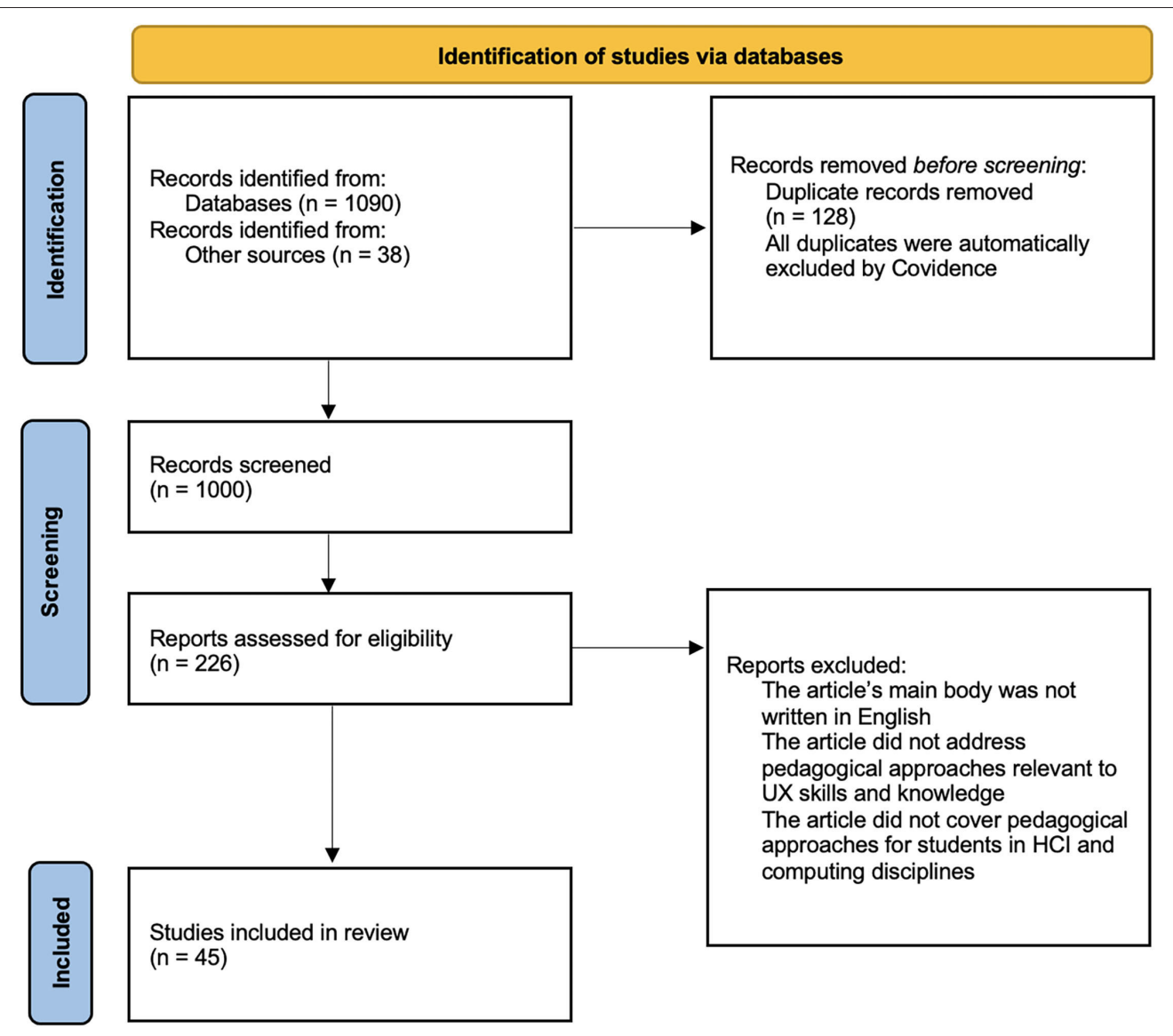

FIGURE 1 | A flow diagram illustrating the article screening process.

We disagreed on 11 articles, which mainly arose due to our mismatched understandings of what disciplines fall under HCI. We resolved the disagreement via discussion. We had a total of 45 articles eligible for data analysis.

\section{ARTICLE BIBLIOGRAPHY PROFILE}

Thirty-seven articles were full research articles, 3 short research articles, 4 symposium articles, and 1 extended abstract. Articles described pedagogical approaches that were based in USA $(n=21)$, European countries $(n=$ 8; Germany, Switzerland, Austria, Denmark, Netherlands, Greece, United Kingdom), Canada $(n=5)$, India $(n=$ $3)$, and others $(n=8$; Chile, Turkey, China, Indonesia, Mexico, Egypt, Australia, Colombia). Articles were published/presented in 30 unique journals and conferences (Table 2). Thirty-seven articles were published/presented in international conferences and eight papers were published in journals.

Articles described pedagogical approaches offered to students in the related department, school, or faculty of Information Technology $(n=7)$, CS and Software Engineering $(n=20)$, Design and Industrial Design $(n=6)$, Computer Graphics
Technology $(n=1)$, and UX $(n=1)$. Three articles said their students came from various STEM fields; seven articles did not clearly indicate the discipline of students, but the authors were from the department of Information Science, $\mathrm{CS}$, and Engineering. Articles were published in the years of 2005-2021 (Figure 2).

\section{RESULTS}

We analyzed each article by summarizing its key information relevant to our RQs: the author, publication year, publication venue, EL type, student benefits and assessment method, and student discipline. We used prior work to identify major EL types described in each article (Gittings et al., 2020). Under this section, we report a comprehensive summary of the reviewed articles, which is a recommended practice (Arksey and O'Malley, 2005), and then we offer a critical overview in relation to the UX education literature in Discussion.

\section{RQ1: Types of Experiential Learning}

Thirty-one articles described pedagogical approaches for undergraduate students, ten articles described pedagogical approaches for graduate students, and four articles described 
TABLE 2 | A list of journals and conference venues.

Venue Name

n

SIGCSE Technical Symposium on Computer Science Education

EduCHI: Annual Symposium on $\mathrm{HCl}$ Education

International Conference on Computers and Accessibility (ASSETS)

International Conference of Design, User Experience, and Usability

Annual Conference on Information Technology Education

Transactions on Computing Education (TOCE)

International Conference on Software Engineering: Software Engineering

Education and Training

Conference on Human Factors in Computing Systems $(\mathrm{CHI})$

World Engineering Education Forum

International Conference on the Foundations of Digital Games

International Conference on Interfaces and $\mathrm{HCl}$

International Journal of Human-Computer Interaction

International Journal of Research on Service-Learning and Community

Engagement

Journal of Usability Studies

International Professional Communication Conference

Health Informatics Journal

Association of Information Science and Technology

IFIP Conference on $\mathrm{HCl}$ (INTERACT)

Interaccion: International Conference on $\mathrm{HCl}$

Designing Interactive Systems Conference (DIS)

Australasian Computing Education Conference

Journal of Engineering Education Transformations

International Conference on MOOCs, Innovation, and Technology in

Education

Koli Calling International Conference on Computing Education Research

Participatory Design Conference

APCHIUX: Asia Pacific Symposium of $\mathrm{HCl}$ and UX Design

Frontiers in Education Conference (FIE)

Western Canadian Conference on Computing Education

International Conference on Teaching, Assessment, and Learning for

Engineering (TALE)

Informatics

\section{Applied Research Project $(n=24)$}

In 24 articles, students were involved in an applied research project. In this project, students were expected to produce minimally functional prototypes or a research report with recommendations. In 17 articles, students worked with industry and community partners or involved end-users. Students or instructors decided on a research topic (vs. industry and community partners). When external partners or end-users were involved, students involved them to a limited degree (either when they conducted usability evaluation or gathering user requirements) and they initiated the initial contact with external partners and end-users.

For instance, in Holzer et al. (2018), students created a prototype that can nudge sustainable campus behaviors and they conducted interviews with potential users only during the design ideation stage. In Zhao et al. (2020), students contacted a person with a disability and they involved the person either to gather user requirements or to conduct usability testing of their design targeted to address accessibility issues.

In three articles, students conducted usability testing with other students. For instance, in Santana-Mancilla et al. (2019), graduate students conducted usability testing of their interactive videogame devices with other teams in class.

In the remaining four articles, end-users were not involved. Notably, Satterfield and Fabri (2017) described an interesting way of "involving" end-users. Their students designed an educational game meant to facilitate social interaction between children without and with autism. Students gathered user requirements by observing preselected YouTube videos to understand children's behaviors.

In 20 articles, an applied research project occurred in a semester-long course (lasting up to 15 weeks). Among these articles, Patil et al.'s (2016) course for CS undergraduate students in India lasted over 4 months. In one article, this EL type occurred in a short course that lasted 2 weeks (Lazem, 2019). Lastly, in three other articles, this EL type occurred in a curriculum.

We found notable variations within this EL type. First, in Koutsabasis and Vosinakis (2012), students engaged in design and research activities, shared ideas, and presented their multitouch interactive table or kiosk prototypes in the virtual world, which was specifically created for the course. Second, some instructors adopted innovative ways to cultivate design thinking in students, for instance, by having to students co-designed with people with and without disabilities (Shinohara et al., 2016) or by having students to team up a student with disability (Zhao et al., 2020).

\section{Industry/Community Research Project $(n=14)$}

In 14 articles, students participated in an industry/community research project. The hallmarks of industry/community research project included: (1) students engaged in intimate collaboration with industry and community partners, starting from project topic inception to iterative design process and final prototype and research report presentation, (2) students sought out to address external partners' needs, and (3) students provided recommendations and prototypes to partners in exchange of learning experience (i.e., monetary compensation was not 


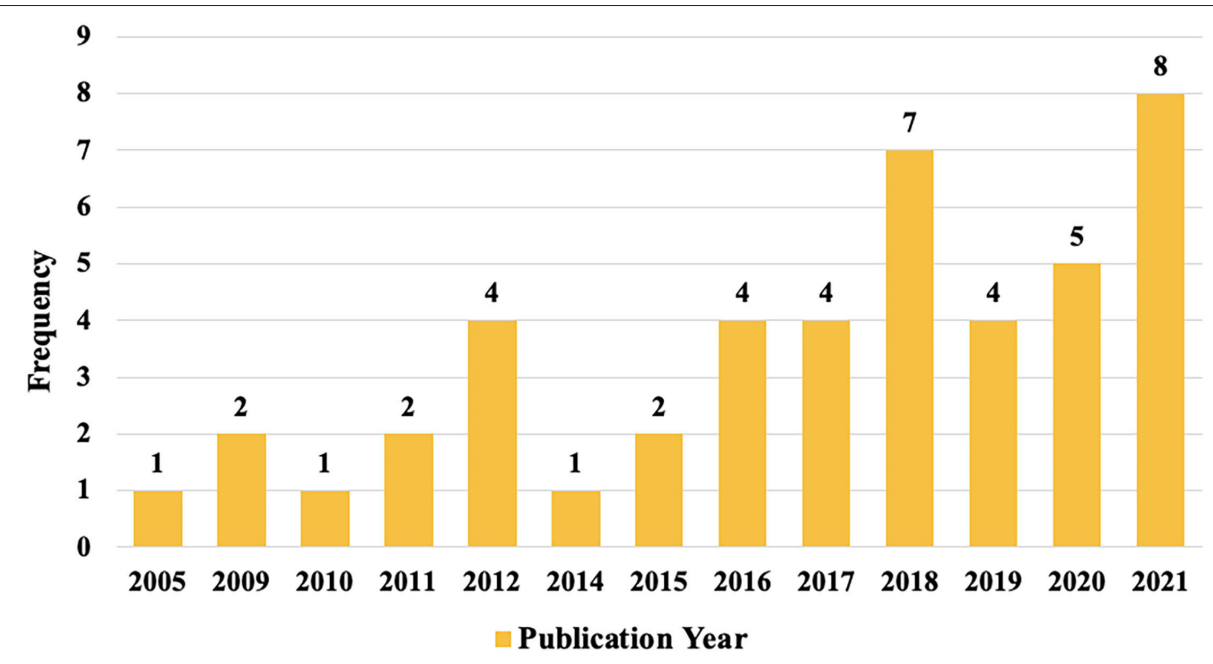

FIGURE 2 | A range of publication years of all articles.

TABLE 3 | The authors of all articles in the review and their corresponding reference number.

\begin{tabular}{|c|c|c|c|}
\hline Ref \# & References & Ref \# & References \\
\hline 2 & Robinson and Hall (2018) & 25 & Lazar (2011) \\
\hline 4 & Péraire (2019) & 27 & Xin et al. (2018) \\
\hline 5 & Byers et al. (2021) & 28 & Kabakova et al. (2021) \\
\hline 8 & Krusche et al. (2018) & 31 & Yargin et al. (2018) \\
\hline 9 & El-Glaly et al. (2020) & 32 & Shinohara et al. (2016) \\
\hline 10 & Konstantinidis et al. (2021) & 33 & Poor et al. (2012) \\
\hline 11 & Koutsabasis and Vosinakis (2012) & 34 & Harrison (2005) \\
\hline 12 & Lazem (2019) & 35 & Shalamova (2016) \\
\hline 17 & Solano (2017) & 40 & Chaffin and Barnes (2010) \\
\hline 18 & Santana-Mancilla et al. (2019) & 41 & Roldan et al. (2021) \\
\hline 19 & Waller et al. (2009) & 42 & Holzer et al. (2018) \\
\hline 20 & Wang (2012) & 43 & Leshed (2019) \\
\hline 21 & Santoso and Sari (2015) & 44 & Shinge et al. (2021) \\
\hline 22 & Mohan et al. (2012) & 45 & Neyem et al. (2014) \\
\hline 23 & Christiansson et al. (2018) & - & - \\
\hline
\end{tabular}

involved). Students designed various interactive systems for their external partners, ranging from serious game applications (Konstantinidis et al., 2021) to a study aid for seniors who study the citizenship exam (Robinson and Hall, 2018) and a mobile recycling application (Leshed, 2019).

In nine articles, students worked on an industry/community research project in a semester-long course (lasting up to 13 weeks). Notably, in Nair (2020), their course in India lasted from 2 weeks to 6 months. In other two articles, students were enrolled in a short course (lasting 4 days) (Xin et al., 2018; Konstantinidis et al., 2021).

We found several variations within this EL type, first regarding the delivery group. In Konstantinidis et al. (2021) and Nair (2020), their courses were offered to international students and 
TABLE 4 | A list of EL types.

\begin{tabular}{|c|c|c|}
\hline EL Type & Description & $n^{*}$ \\
\hline $\begin{array}{l}\text { Applied research } \\
\text { project }\end{array}$ & $\begin{array}{l}\text { Students conduct a real-world project without } \\
\text { external partners, but they can involve partners if } \\
\text { they wish. }\end{array}$ & 24 \\
\hline $\begin{array}{l}\text { Industry/community } \\
\text { research project }\end{array}$ & $\begin{array}{l}\text { Students collaborate on a project with industry and } \\
\text { community partners in the exchange of their } \\
\text { learning experience. }\end{array}$ & 14 \\
\hline Hands-on activity & $\begin{array}{l}\text { Students are presented with real-world scenarios in } \\
\text { a classroom or an outside-of-classroom setting. }\end{array}$ & 3 \\
\hline Role-play & $\begin{array}{l}\text { Students assume a particular role and perform its } \\
\text { associated responsibility to complete a task. }\end{array}$ & 2 \\
\hline Interactive workshop & $\begin{array}{l}\text { Experts are invited to provide interactive learning } \\
\text { experience or students can also lead a workshop. }\end{array}$ & 3 \\
\hline Guest speakers & $\begin{array}{l}\text { Guest speakers who are not instructors share their } \\
\text { expertise with students. }\end{array}$ & 2 \\
\hline $\begin{array}{l}\text { In-house work } \\
\text { placement }\end{array}$ & $\begin{array}{l}\text { Students spend time doing real work through } \\
\text { university and receive payment via university } \\
\text { account. }\end{array}$ & 1 \\
\hline Internship & $\begin{array}{l}\text { Student spend time doing real work for a real } \\
\text { business in their relevant field. }\end{array}$ & 1 \\
\hline Flipped classroom & $\begin{array}{l}\text { Students watch video lectures outside of class and } \\
\text { engage with real-world scenarios in a classroom } \\
\text { setting. }\end{array}$ & 2 \\
\hline Field project & $\begin{array}{l}\text { Students make a field visit to industry practitioners } \\
\text { outside of classroom setting. }\end{array}$ & 1 \\
\hline Lab & $\begin{array}{l}\text { Students engage in practical application of skills } \\
\text { within a classroom setting. }\end{array}$ & 1 \\
\hline Design hackathon & $\begin{array}{l}\text { Students engage in a project with industry partners } \\
\text { over a short period of time. }\end{array}$ & 1 \\
\hline \multirow[t]{6}{*}{ Combined practice } & Industry/community research project and role-play & \\
\hline & $\begin{array}{l}\text { Flipped classroom, applied research project, field } \\
\text { trip, and guest speakers }\end{array}$ & \\
\hline & $\begin{array}{l}\text { Industry/community research project and interactive } \\
\text { workshop }\end{array}$ & \\
\hline & $\begin{array}{l}\text { Applied research project, industry/community } \\
\text { research project, and design hackathon }\end{array}$ & \\
\hline & $\begin{array}{l}\text { Applied research project and industry/community } \\
\text { research project }\end{array}$ & \\
\hline & $\begin{array}{l}\text { Internship, interactive workshop, and guest } \\
\text { speakers }\end{array}$ & \\
\hline
\end{tabular}

*We treated each EL type appeared in a given article as a unique count and the frequency of all EL types does not add up to a total number of articles. Some articles describe more than one EL type (i.e., articles that presented more than one EL type).

other university researchers in addition to their students in the department of engineering. Second, in Vorvoreanu et al. (2017), their experiential studio invited students of all levels-freshmen, sophomore, and junior-to work on an industry-sponsored partners (i.e., cross-cohort teamwork).

Second, in certain courses, students who worked with local communities worked on projects that were more socially driven. In Shinge et al. (2021), students designed a new digital method of teaching to improve elementary school children's poor performance across basic subjects. In Nair (2020), students provided technology remedies for pressing issues such as sanitation, potable water and nutrition faced in village communities in India.
This EL type also occurred in an independent training program. Kang et al. (2021) described a training program called the Research and Education in Accessibility, Design and Innovation (READi). Students concurrently pursued their home degree program while participating in these programs. They worked with community partners for 8 months and they provide tangible insights to partners' accessibility issues.

Regardless of whether students were embedded in a semesterlong course, a short course, a curriculum, or an independent training program, students performed all or some of the following key UX activities that closely follow the real-world UX project lifespan: (1) requirement gathering (e.g., stakeholder identification and interviews, stakeholder map, persona); (2) design (e.g., iterative prototyping), (3) usability evaluation (e.g., focus group, experiment, affinity mapping, user journey, accessibility evaluation), and (4) implementation (e.g., prototype and presentation to clients).

\section{Hands-on Activity $(n=3)$}

This EL type provided students with real-world scenarios and challenges. In Hui (2020), students identified four real-world design challenges and, in teams, provided solution to each challenge. Students also conducted heuristic evaluation on one of the prototypes created from a design challenge. Lallemand (2021) presented three creative hands-on activities to teach students about research methods. One notable activity is called a SelfExploration of Methods Booklet. The booklet presents a real user study that employed UX methods (e.g., AttrakDiff scale, Geneva Emotion Wheel) to evaluate design concepts. Students participate in the study as if they are a real study participant and then they critically evaluate each method.

\section{Role-Play $(n=2)$}

In this EL type, students performed a certain role and its corresponding responsibilities to complete a task. Krusche et al. (2018) introduced "software theater" in which undergraduate students role-played as actors of the screenplay and they played out how end-users would use the new product and services in the real world. In Robinson and Hall (2018) agile development methods class, students formed a scrum team and took on roles as SCRUM Master, Product Owner, UI Designer, Tester, or other roles essential in scrum and they carried out an industry/community research project.

\section{Interactive Workshop $(n=3)$}

Interactive workshops invited students to lead a class or participate in hands-on activities. In Leshed's (2019) advanced HCI course, students were the drivers of the class; they planned and led a workshop on a given topic. Students were encouraged to be creative with the pedagogical method for the workshop, such as craft exercises, field trips, performing arts, and cooking.

In two independent training programs-READi (Kang et al., 2021) and Collaborative Leaning of Usability Experiences (CLUE) (Girouard and Kang, 2021)-accessibility and UX experts from industry and academia delivered a workshop and students participated in hands-on activities to learn about relevant topics, including web and document accessibility; 
TABLE 5 | A list of EL type and respective reference.

\begin{tabular}{|c|c|c|c|c|c|}
\hline Ref \# & Student level & Format & Central Topics Taught & Duration & EL type \\
\hline 1 & $U$ & $\begin{array}{l}\text { Outside-of-class } \\
\text { lab activity }\end{array}$ & UX research, design, and evaluation & Not indicated & In-house work placement \\
\hline 2 & $\mathrm{U}$ (3rd and 4th) & Course & $\begin{array}{l}\text { Rapid prototyping, project management, } \\
\text { teamwork }\end{array}$ & Semester & $\begin{array}{l}\text { Industry/community research project, } \\
\text { and role-play }\end{array}$ \\
\hline 3 & U (3rd and 4th) & Course ${ }^{\star \star}$ & $\begin{array}{l}\mathrm{HCl} \text { theories; } \mathrm{HCl} \text { research, design, } \\
\text { evaluation }\end{array}$ & Semester & $\begin{array}{l}\text { Industry/community research project, } \\
\text { hands-on activity }\end{array}$ \\
\hline 4 & G (Master's) & Course & $\begin{array}{l}\text { Requirements engineering, interaction } \\
\text { design }\end{array}$ & Semester & $\begin{array}{l}\text { Flipped classroom, applied research } \\
\text { project, field project, and guest } \\
\text { speakers }\end{array}$ \\
\hline 5 & G & Course & Inclusive design & Semester & Applied research project \\
\hline 6 & $\mathrm{U}($ 2nd and $3 \mathrm{rd})$ & Course & User evaluation methods & Semester & Hands-on activity \\
\hline 7 & $U$ and $\mathrm{G}$ & Course & $\mathrm{HCl}$ research, design, evaluation & Semester & Applied research project \\
\hline 8 & $U$ & Course $^{\star}$ & Software design and development & Semester & Role-play \\
\hline 9 & U (1st and 2nd) & Lab & Accessibility & 20-60 min per activity & $\mathrm{Lab}$ \\
\hline 10 & $U$ & Short course & User-centered design & 4 days & Industry/community research project \\
\hline 11 & G (Master's) & Course & $\mathrm{HCl}$ research, design, evaluation & Semester & Applied research project \\
\hline 12 & $U$ & Short course & $\mathrm{HCl}$ research, design, evaluation & 2 weeks & Applied research project \\
\hline 13 & G (Master's and Doctoral) & Training program & $\begin{array}{l}\text { Accessibility, } \mathrm{HCl} \text { design, research, and } \\
\text { evaluation }\end{array}$ & $1-4$ years & $\begin{array}{l}\text { Industry/community research project } \\
\text { and interactive workshops }\end{array}$ \\
\hline 14 & $U$ & Curriculum & Design thinking & 3 years & $\begin{array}{l}\text { Design hackathon, applied research } \\
\text { project, industry/community research } \\
\text { project }\end{array}$ \\
\hline 15 & $U$ & Course & $\mathrm{HCl}$ research, design, evaluation & Semester & Industry/community research project \\
\hline 16 & $U$ and $\mathrm{G}$ & Course $^{\star}$ & $\mathrm{HCl}$ research, design, evaluation & Semester & Flipped classroom \\
\hline 17 & $U$ & Course & $\mathrm{HCl}$ research, design, evaluation & Semester & Applied research project \\
\hline
\end{tabular}

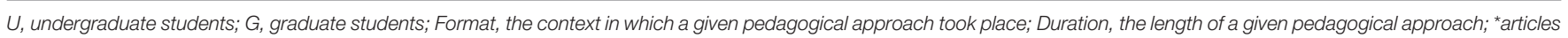
have applied a given EL type in various courses; **articles that have used different EL types in the same course in different year.

design thinking; and assistive and adaptive technologies, entrepreneurship, and interpersonal skills.

\section{Guest Speakers $(n=2)$}

Two articles invited guest speakers to bring the real world to the classroom and offer students an outside perspective. Girouard and Kang (2021) stated CLUE regularly hosted guest speakers to talk about their recent HCI and UX research projects. Similarly, Péraire (2019) invited a guest speaker on interaction design in industry.

\section{Flipped Classroom $(n=2)$}

In a flipped classroom, students watched video lectures outside of class and they dedicated in-class time on interactive group learning activities. Instructors created video lectures or pulled them from web sources, such as YouTube and Coursera. In the beginning of class, instructors used online quiz and spent 15-30 min to check students understanding.

As an example, in Maher et al.'s (2015) class, students engaged in class activities designed to improve UX competencies. When learning about needfinding, one or two students in a group developed a persona and they role-played as a user while other students in the group prepared interview questions and conducted an interview with "the user."

\section{Internship $(n=1)$}

An internship was observed in one article that introduced the CLUE training program (Girouard and Kang, 2021). Students in CLUE undertook paid UX Internships. They worked with leading UX experts from industry and government for 8month (part-time) or 4-months (full-time). Students took on various roles, such as UX architect, Design Researcher, Human Factors Researcher, UI Designer, UX Programmer, and Business Intelligence Analyst.

\section{$\operatorname{Lab}(n=1)$}

El-Glaly et al. (2020) created online accessibility lab activities that can be embedded in various computing classes. Each lab activity addresses five topics: (1) deaf/hard of hearing, (3) color blindness, (3) blindness, (4) dexterity issues, and (5) cognitive impairment. Students go through each lab with and without an emulation feature meant to simulate a given accessibility condition.

\section{In-house Work Placement $(n=1)$}

Talone et al. (2017) described a UX lab that is led by a faculty mentor. Undergraduate students in the department of Information work as a part-time, paid UX consultant under the mentorship of the faculty mentor and graduate students who are experienced in HCI and UX. They work with local companies (often software developers) and offer various UX 
TABLE 6 | A list of EL type and respective reference.

\begin{tabular}{|c|c|c|c|c|c|}
\hline Ref \# & Student level & Format & Central topics taught & Duration & EL type \\
\hline 18 & $\mathrm{U}$ (3rd and 4th) & Course & $\mathrm{HCl}$ research, design, evaluation & Semester & Applied research project \\
\hline 19 & $U$ & Curriculum & Accessibility, software design and development & 4 years & Applied research project \\
\hline 20 & U (1st and 2nd) & Course & Web design, accessibility & Semester & Applied research project \\
\hline 21 & $\mathrm{U}$ (3rd and 4th) & Course & $\mathrm{HCl}$ research, design, evaluation & Semester & Applied research project \\
\hline 22 & $\mathrm{U}$ (3rd and 4th) & Curriculum & Software design and development & 2 years & $\begin{array}{l}\text { Applied research project and } \\
\text { industry/community research } \\
\text { project }\end{array}$ \\
\hline 23 & U (1st and 2nd) & Course & Co-design and participatory method & Semester & Applied research project \\
\hline 24 & G (Master's and Doctoral) & Training program & UX & $2-4$ years & $\begin{array}{l}\text { Internship, guest speakers, and } \\
\text { interactive workshops }\end{array}$ \\
\hline 25 & $U$ & Course $^{\star}$ & $\mathrm{HCl}$ research, design, evaluation & Semester & $\begin{array}{l}\text { Industry/community research } \\
\text { project }\end{array}$ \\
\hline 26 & G (Master's) & Course* $^{*}$ & UX research, design, evaluation & Semester & $\begin{array}{l}\text { Industry/community research } \\
\text { project }\end{array}$ \\
\hline 27 & G (Master's) & Short course & UX research, design, evaluation & $\begin{array}{l}4 \text { days; project } \\
\text { spanned over } 45 \\
\text { days }\end{array}$ & $\begin{array}{l}\text { Industry/community research } \\
\text { project }\end{array}$ \\
\hline 28 & G (Master's) & Course $^{\star}$ & UX research, design, evaluation & Semester & $\begin{array}{l}\text { Industry/community research } \\
\text { project }\end{array}$ \\
\hline 29 & U (2nd and 3rd) & Course & $\mathrm{HCl}$ research, design, evaluation; accessibility & Semester & Applied research project \\
\hline 30 & $\cup(a l l)$ & Studio & UX research, design, evaluation & Semester & $\begin{array}{l}\text { Industry/community research } \\
\text { project }\end{array}$ \\
\hline 31 & G & Course & UX research, design, evaluation & Semester & Applied research project \\
\hline 32 & $U$ & Course & Design thinking & Semester & Applied research project \\
\hline 33 & U (2nd and 3rd) & Course & Accessibility engineering, UI, usability & Semester & Applied research project \\
\hline 34 & $U$ & Course & Web design, accessibility & Semester & Applied research project \\
\hline 35 & U (1st and 2nd) & Course & UX theory, engineering, designing thinking & Semester & Hands-on activity \\
\hline
\end{tabular}

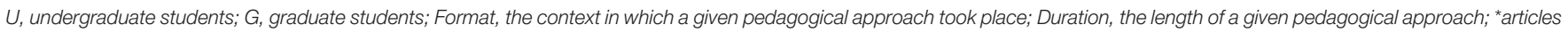
have applied a given EL type in various courses.

TABLE 7 | A list of EL type and respective reference.

\begin{tabular}{|c|c|c|c|c|c|}
\hline Ref \# & Student level & Format & Central topics taught & Duration & EL type \\
\hline 36 & U (3rd and 4th) & Course & Inclusive design and research & Semester & Applied research project \\
\hline 37 & U (3rd and 4th) & Course & UX research, design, evaluation & Semester & Applied research project \\
\hline 38 & U (3rd and 4th) & Course & Human-centered design and research & Semester & Industry/community research project \\
\hline 39 & U (2nd and 3rd) & Course & User-centered design, usability, UI & Semester & Applied research project \\
\hline 40 & $\mathrm{U}$ and $\mathrm{G}$ (3rd and 4th) & Course & Software design and development & Semester & Applied research project \\
\hline 41 & G (Master's) & Course & Human-centered design and research & Semester & Applied research project \\
\hline 42 & U (3rd and 4th) & Course & Design thinking & Semester & Applied research project \\
\hline 43 & $\begin{array}{l}U \text { and } \mathrm{G} \text { (3rd and } 4 \text { th and } \\
\text { Master's) }\end{array}$ & Course & $\mathrm{HCl}$ research, design, evaluation & Semester & Interactive workshop \\
\hline 44 & U (1st and 2nd) & Course & Human-centered design and research & Semester & Industry/community research project \\
\hline 45 & U (3rd and 4th) & Course & Software design and development & Semester & Industry/community research project \\
\hline
\end{tabular}

U, undergraduate students; G, graduate students; Format, the context in which a given pedagogical approach took place; Duration, the length of a given pedagogical approach.

services that fall under three areas: user testing, user research, and design evaluation.

\section{Design Hackathon $(n=1)$}

Hardy et al. (2018) incorporated a 2-day design hackathon called Design Sprint. Students of all levels worked with startups and companies to develop a solution for their needs. Students engaged in four design processes-user gathering requirements, ideate, develop, and test prototypes. In the end, students prepared a 3-min pitch of their prototype to judges evaluated based on creativity, best use of technology, and best problem-solving approach. 


\section{Field Project $(n=1)$}

This EL type nudged students to visit industry practitioners in their working environment. Péraire (2019) asked students in teams to interview two real industry practitioners from Silicon Valley companies working on the same product. One practitioner has to be in requirements (e.g., Product Manager, Product Owner) and one practitioner had to assume user experience (e.g., Interaction Designer, Product Designer).

\section{Combined Practice}

In six articles, above-mentioned EL types occurred in combination: (1) industry/community research project and role-play (Robinson and Hall, 2018), (2) flipped classroom, applied research project, guest speakers, and field project (Péraire, 2019), (3) industry/community research project and interactive workshops (Kang et al., 2021), (4) applied research project, industry/community research project, and design hackathon (Hardy et al., 2018), (5) applied research project and industry/community research project (Mohan et al., 2012), and (6) internships, guest speakers, and interactive workshop (Girouard and Kang, 2021).

\section{RQ2: Learning Outcomes}

The authors of 26 articles provided student learning outcomes (Tables 8-10). From these articles, we extracted major cognitive and affective learning outcomes. Cognitive learning outcomes are students' gain on technical and conceptual knowledge on a given topic. Affective learning outcomes are students attitude toward an instructor, a course, or a learning environment (Wei et al., 2021). In addition, we extracted major students benefits that did not fall within the definition of cognitive and affective learning outcomes.

Most commonly used assessment methods were student final course evaluation $(n=10)$, pre- and post-survey $(n=5)$, student reflections $(n=4)$, combination $(n=3)$, student course work $(n$ $=2)$, student exit interviews $(n=1)$, and student performance evaluation $(n=1)$.

A few studies are noteworthy in terms of the comprehensiveness of their assessment. El-Glaly et al. (2020) conducted an experiment to evaluate the effectiveness of their hands-on accessibility lab activities with a group of 276 students. In this study, there were three experimental conditions. Students in Group A did not go through the lab. Students in Group B went through the lab. Students in Group C went through the lab plus they received Supplementary Materials meant to cultivate empathy toward people with disability. Zhao et al. (2020) conducted a 4-year longitudinal study with a final sample size of 412 students. They assigned students to four different accessibility education interventions and recorded students' changes in knowledge from the start and the end of the course.

We identified 6 patterns across the reported learning outcomes (Figure 3). Note that most articles reported on several student learning outcomes and benefits fell under more than one pattern. Thus, some articles appear across several patterns.

First, students improved on UX technical knowledge $(n=15)$, including improved knowledge and skills on UX concepts (e.g., MacDonald and Rozaklis, 2017) and human-centered research
TABLE 8 | A list of learning outcomes and benefits reported in the articles.

\begin{tabular}{lll}
\hline Ref \# Student learning outcomes and benefits & $\begin{array}{l}\text { Assessment } \\
\text { method }\end{array}$
\end{tabular}

$1 \quad$ Students improved their job marketability, Student reflections improved ability to work in a professional setting, and acquired soft skills; they applied coursework to real-world project.

2 Students understood the importance of good teamwork, valued the learn-by-doing, and understood the complexities of working as a team.

3 Students realized real-world design challenge is complex to solve in practice and found the course interesting or relevant to real world applications.

4 Students valued the learn-by-doing approach.

$5 \quad$ Students gained professional experience and improved design and research skills.

6 Students learned about new research methods in a rapid and fun way; they liked applying textbook knowledge to solve real-world challenges; they liked creating the video on a chosen research method and learning from other groups' videos.

7 Undergraduate students valued the graduate student mentorship; graduate students learned about the UX evaluation process and the complexities involved in the UX process including, delays, and incomplete prototypes.

8 Students improved their demo management skills and found software theater creative, fun, dynamic, understandable, memorable, and engaging.

9 Students who were in hands-on accessibility labs had more positive attitude toward creating accessible software and had higher quiz scores on accessibility topics than students who were not exposed to the labs.

10 Students enjoyed the course, they learned a lot, and they did not find the lecture difficult.

12 Students were intellectually stimulated and learned new ideas and skills; they were satisfied with final course project and teamwork; they applied knowledge to practice.

16 Students felt they learned more during and outside of class time compared to previous courses.

18 Students learned the required $\mathrm{HCl}$ skills through Student final course the design and development of videogames; they evaluation had positive attitude toward using videogames for skill development in higher education, and they enjoyed learning using computer games.
Student final course evaluation

Student final course evaluation

Student reflections

Student reflections

Student exit

interviews

Student final course evaluation

Pre- and Post-Survey

Student final course evaluation

Student final course evaluation

Student final course evaluation

.

\section{Student reflections}

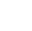


TABLE 9 | A list of learning outcomes and benefits reported in the articles.

\section{Ref \# Student learning outcomes and benefits Assessment method}

21 Students valued authentic learning experience via applied research project and lecturer who shared their real-world UX experiences.

24 Students were positively evaluated on dependability, self-reflectional capacity, team work, independence, and professionalism by UX internship mentors.

26 Students improved on: their knowledge of UX concepts/methods, ability to create quality deliverables, ability to work in teams and with clients, ability to work within time/resource constraints, interest in UX, confidence in applying UX methods, and ability to manage the "messiness" of real-world projects. Students were satisfied with UX project participation.

Students felt more prepared for UX employment and their experience made them more marketable to employers.

28 Students developed soft skills (e.g., project management, storytelling, empathy, collaboration) and UXD skills (i.e., communication with stakeholders, data management, domain knowledge, and comfort with ambiguity in face of wicked problems); they applied theory to real-world problems; they understood non-profit work; they showed a better understanding of own strengths/weakness. Students felt prepared for employment and developed a professional identity. Students valued user diversity and developed social network. individuals who use accessible technologies, greater awareness of assistive technologies, and greater technical knowledge of accessible programming techniques.

30 Students showed improvement on: defining human-centered design, collecting data from users, finding appropriate problems to solve, defending solutions to stakeholders, and creating compelling prototypes.

32 Students broadened their perception of and importance of inaccessibility in design and learned the etiquette of interaction with people with disabilities); they learned to balance functional and non-functional factors (e.g., aesthetics, safety) in a design for people with and without disabilities; they showed changed attitudes toward design for people with disability and embraced universal design. accessibility (i.e., understood the implications

\section{Student final course} evaluation

Student performance evaluation

Pre- and Post-Survey

Student reflections and

Student final course evaluation

$\begin{aligned} & \text { Assessment } \\ & \text { method }\end{aligned}$
$\begin{aligned} & \text { Student final course } \\ & \text { evaluation }\end{aligned}$
$\begin{aligned} & \text { Student performance } \\ & \text { evaluation }\end{aligned}$

37 Students showed high performance on major UX activities.

39 Students found the course very interesting and the course invited deeper involvement with the subject area.

40 Students improved on their programming skills and showed increased knowledge of art concepts including creating animated sprites, tile sets, and GUI development.

Students felt prepared for their long-term goal (e.g., grad school or game industry).

41 Students understood the techniques and tips behind working with and engaging end-users

42 Students were satisfied with the course; they expanded their perspectives; they enjoyed collaboration and interdisciplinarity group work; they improved on feedback and presentation skills.

Pre- and Post-Survey

Pre- and Post-Survey

Student coursework

(Robinson and Hall, 2018) and enhanced interpersonal and communication skill with people with disabilities (Shinohara et al., 2016) and stakeholders (Gray et al., 2019).

Fourth, students became more aware of the needs of diverse end-users $(n=5)$. They showed positive attitude toward creating accessible software (El-Glaly et al., 2020) and understood the implications of inaccessibility (Shinohara et al., 2016). Fifth, students reported to become more marketable to employers, developed a professional identity, and feel prepared for their long-term career goals $(n=4)$ (MacDonald and Rozaklis, 2017; Talone et al., 2017; Kabakova et al., 2021).

Lastly, students expressed satisfaction toward various aspects of a given pedagogical approach $(n=10)$, including UX project participation (MacDonald and Rozaklis, 2017), graduate student mentorship (Brown and Pastel, 2009), and the use of videogames as a teaching tool (Santana-Mancilla et al., 2019).

\section{DISCUSSION}

doing so, they realized the messiness of solving real world design challenge and evaluating prototypes. Third, students acquired soft skills $(n=10)$, including demo management skill (Krusche et al., 2018), time and resource management (MacDonald and Rozaklis, 2017), and storytelling and empathy (Kabakova et al., 2021). Students also valued the importance of good teamwork

\section{Immersive and Non-immersive Experiential Learning}

In response to the RQ1, the scoping review shows 12 EL types were used to teach UX in higher education. The review suggests five EL types are more immersive than others, mainly applied research project, industry/community research project, in-house 


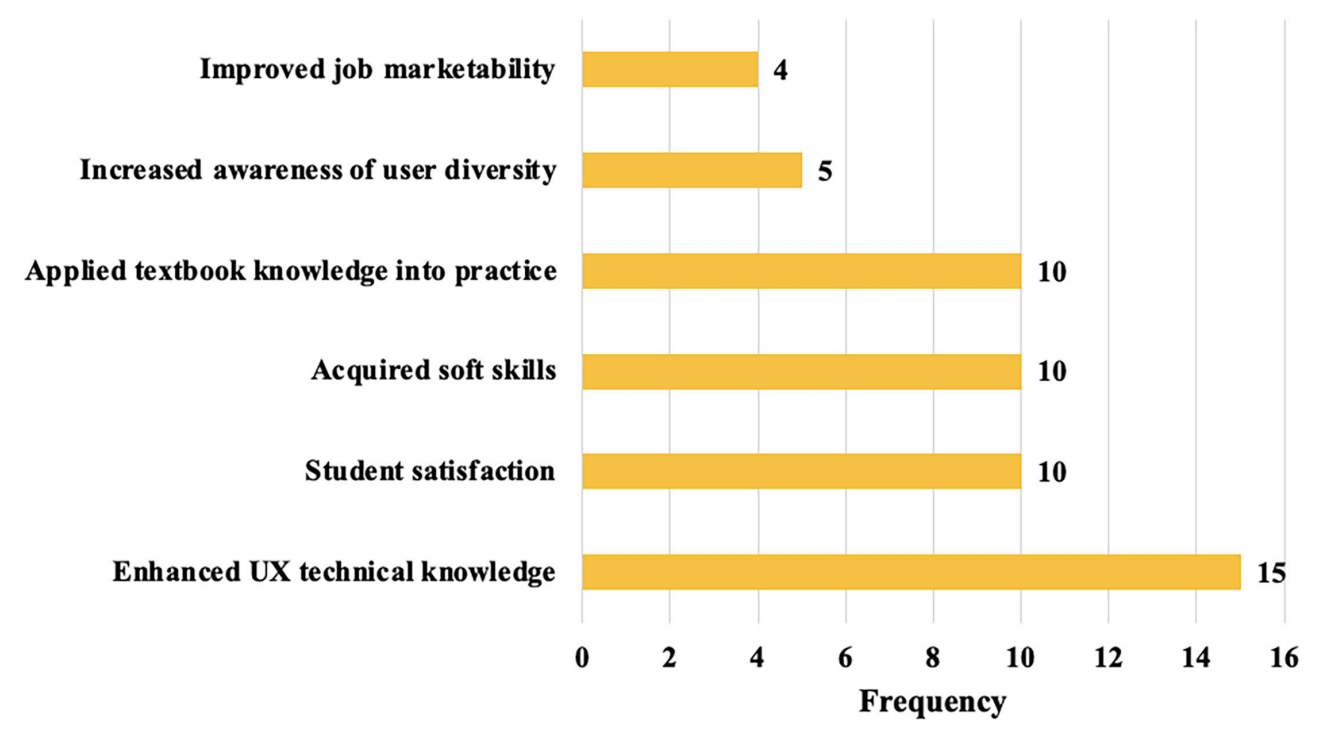

FIGURE 3 | A list of student learning outcomes and benefits from participating in EL.

work placement, internship, and design hackathon. In these immersive EL types, students interact with actual end-users and clients for a prolonged period of time, with the exception of a 2-day design hackathon.

Getto and Beecher (2016) proposed four components a student should go through to learn about UX. Orientation is when a student is introduced to basic UX principles. During the observation stage, a student observes experienced UX practitioners "in action" and ask them about what they did and why. During the practice and play stages, a student applies their UX knowledge to tackle real usability problems and putting their own spin on the methods.

In the current review, these four components were presented especially in UX internships and in-house work placement. In these two immersive EL types, students monitor closely their UX industry mentors (Girouard and Kang, 2021) and faculty advisor (Talone et al., 2017) (orientation and observation). They then practice and refine diverse UX skills with actual client projects, ranging from persona creation, user requirements, and A/B testing (practice and play).

These four components in immersive EL types may afford students with a unique set of learning outcomes and benefits. The current review shows three learning outcomes and benefits are mainly associated with immersive EL types: increased job marketability, increased awareness of user diversity, and development of certain soft skills, including learning etiquette of interacting with diverse user groups, handling messiness of real UX projects, and working under the constraints.

After participating in immersive EL types, students acquire a vital tangible outcome: a professional portfolio that showcases their UX projects to future employers. There is a discrepancy between the actual skills possessed by HCI graduates and the expected skills in these graduates by hiring managers and employers (Radermacher and Walia, 2013; Gonzalez et al., 2014).
In general, employers are more attracted to new graduates with work experiences than graduate without the experiences (Chi and Gursoy, 2009).

By being able to showcase their UX proficiency via portfolio, students become more attractive candidates to employers. Relatedly, increased awareness of user diversity and soft skills related to user groups can only come from working with real endusers and clients, a core feature that is missed in non-immersive EL types.

However, we remain cautious in confidently mapping the relationship between immersive EL types and specific learning outcomes and benefits. The current review had a higher number of articles that focused on immersive EL types than nonimmersive ones. This screwed representation can indicate the current gap in UX education literature and this highlights more efforts from the HCI community as a whole is needed to establish a pedagogy culture, so HCI educators are intrinsically motivated to share their UX pedagogy for all student levels.

\section{Relationship Between Student Levels and Experiential Learning}

For the articles that focused on undergraduate students, we did not observe the following EL types: field project, flipped classroom, internship, guest speakers, and interactive workshop. For the article that focused on graduate students and graduate and undergraduate students combined, we did not observe the following EL types: in-house work placement, lab, role-play, design hackathon, and hands-on activity. Are some EL types more suitable for graduate students over undergraduate students and vice versa?

Graduate and undergraduate students show differences on various skills, including critical thinking (Artino and Stephens, 2009) and task efficiency (Daun et al., 2015). Given this knowledge, interactive workshops, hands-on activity, lab, and 
flipped classroom might not be appropriate for lower-level undergraduate students. They require students to take control of their learning outside of class and students need to readily engage in discussion. Lower-level undergraduate students can lack training on those skills to benefit from those EL types. Hands-on activity and lab that were reviewed in the current scoping review is a great way to introduce foundational UX concepts to lower-level undergraduates but not for graduate students and upper-level undergraduate students.

Role-play and design hackathon can be useful for students of all levels. In the current review, role-play occurred in combination with industry/community research projects and having students to take on real a UX practitioner role can enhance the degree of student immersion. Design hackathon allows for peer learning opportunities where junior students learn from senior students.

\section{Current Gaps in UX Education Literature Need for Advanced Research Design, Analysis, and Report}

In response to the RQ2, the current review identified six student learning outcomes and benefits from participating in experiential learning. The review also identified seven assessment methods, which are comparable to what other systematic reviews have found (Wei et al., 2021).

Most articles that examined student learning outcomes and benefits had smaller sample sizes compared to non-education related research studies published at a leading HCI conference. In the review, for studies that employed qualitative assessment methods, the mean of a sample size was 19 students (vs. the mean of a sample size was 55 participants in other studies). For studies that employed quantitative assessment methods, the mean of a sample size of 136 students (vs. the mean of a sample size was 224 participants in other studies) (Caine, 2016). Hence, all assessment methods, be it qualitative or quantitative, had lower sample sizes compared to the reported standard.

Having small sample size is understandable; most articles examined the short-term impact of their UX pedagogy with one group of students enrolled in their course for a semester. For qualitative assessment methods, a high sample size allows for the discovery of new themes centering on student learning outcomes and benefits. For quantitative assessment methods, a high sample size ensures researchers have a good statistical power to detect for potential differences between students enrolled in different educational intervention groups or potential differences in student learning outcomes in a pre- and post-survey study design. HCI educators can conduct a longitudinal and recruit multiple student groups across multiple semesters. This study design would allow for higher sample sizes.

We also note the lack of depth in final course evaluation questionnaires. These questionnaires either focused on course logistics or they were too simple (e.g., how much did you learn?). This lack of depth is understandable, given the focus was the description of their pedagogical approaches. In future, $\mathrm{HCI}$ educators can consider incorporating more comprehensive learning assessment methods as seen in El-Glaly et al. (2020) and Zhao et al. (2020).
Lastly, we highlight inadequate reporting practices; a few articles that did not report important study details, including student levels and the type and process of qualitative analysis employed, and a sample size. For instance, $27 \%$ of articles that provided learning assessment did not report on their sample size. Comprehensive reporting helps other researchers to map the relationships between study characteristics. Future work should report as many details of their UX pedagogy as possible.

\section{Need to Understand the Effect of Different EL Types}

The next step is to compare the long-term effects of different EL types and this comparison can determine which EL type is superior over another type. In this review, none of the articles experimentally compared different EL types. A few articles who provided rigorous student assessment were limited to comparing students in a control condition against students exposed to their UX pedagogy (e.g., El-Glaly et al., 2020). Zhao et al. (2020) compared the effect of variations of applied research projects and they found only the students who did not interact with end-users retained HCI knowledge after 2 years a course had finished. With the current review serving as a guideline, HCI educators can conduct longitudinal experiments and determine how different EL types compared to one another in UX knowledge attainment long-term.

Another relevant area of investigation is understanding the effect of combined EL types (vs. one EL type). In this review, 6 articles described how they offered a combination of different EL types. Scott et al. (2019) showed students who completed more than one EL type rated their writing skills higher and reported better quality of relationship with faculty than students who completed one EL type. Students who undergo combined EL types can continuously reinforce their UX knowledge over a long period of time. This area of investigation can assist HCI educators to strategically design their curriculum. Taking one EL type may not be sufficient to develop full UX competencies.

\section{Practical Implications for $\mathrm{HCl}$ Educators}

With 12 EL types identified in the review, we offer practical recommendations for HCI educators. HCI educators need to consider their own resources and constraints in implementing these immersive EL types. In all articles that have incorporated an industry/community research project, they have already established a partnership with local companies and organizations. In some cases, faculty have received an external funding to support an independent training program. For instance, Girouard and Kang (2021) mentioned that CLUE had initially established 33 industry and government partnerships to support students' UX internships.

One recommendation for starting partnerships is reaching out to UX professional associations and connect with willing partners. Getto and Beecher (2016) have recommended UX associations, such as Interaction Design Association (IxDA), the User Experience Professionals Association (UXPA), and the Information Architecture Institute. 
When involving external partners is not feasible, having students to work on an applied research project can be an ideal approach. Some articles mentioned that it was students who reached out to target users and this student initiation can reduce the pressure off from the instructors. We also saw the use of YouTube videos to expose students to target users (Maher et al., 2015).

\section{Study Limitations}

There are two limitations. First, our review is limited to finding articles from three databases, mainly IEEE, ACM, and Scorpus. While these three are top databases in the fields of HCI and social science, there is a possibility of missed articles that discuss UX pedagogical approaches. In attempt to expand our pool of articles beyond these three databases, we conducted additional manual search via Google Scholar and backward reference checking. Moreover, our review is limited to articles published in English, which makes one wonder about other UX pedagogical approaches written in non-English languages.

Relatedly, threat to limited coverage is also raised by a possibility that HCI educators and researchers may not publish their work about their UX pedagogical approaches. That is, there could be more courses being taught than published papers about the course. Published work on any topics related to experiential learning is rarely seen at leading HCI conferences (e.g., CHI) (Lee et al., 2019; Lima et al., 2021). Many HCI scholars may not see publishing about teaching practices as a "hot" HCI area. If so, it would be important to consider how universities and the HCI community at large can change such perception.

Second, we want to acknowledge that some articles described a lecture component in their pedagogical approaches. A lecture can be highly experiential. But it was impossible to discern from reading the article whether the lecture component was experiential.

\section{REFERENCES}

ACM (2020). Computing Curricula 2020 Paradigms for Global Computing Education. Available online at: https://www.acm.org/binaries/content/assets/ education/curricula-recommendations/cc2020.pdf (accessed July 01, 2021).

Arksey, H., and O'Malley, L. (2005). Scoping studies: towards a methodological framework. Int. J. Soc. Res. Methodol. 8, 19-32. doi: 10.1080/1364557032000119616

Artino, A. R., and Stephens, J. M. (2009). Academic motivation and self-regulation: a comparative analysis of undergraduate and graduate students learning online. Internet Higher Educ. 12:1. doi: 10.1016/j.iheduc.2009.02.001

Barr, T. F., and McNeilly, K. M. (2002). The value of students' classroom experiences from the eyes of the recruiter: information, implications, and recommendations for marketing educators. J. Market. Educ. 24, 168-173. doi: $10.1177 / 0273475302242010$

Brechner, E. (2003). "Things they would not teach me of in college: what Microsoft developers learn later," in Proceedings of the Conference on Object-Oriented Programming Systems, Languages, and Applications (Anaheim, CA), 134-136. doi: $10.1145 / 949344.949387$

Brown, C., and Pastel, R. (2009). "Combining distinct graduate and undergraduate HCI courses: an experiential and interactive approach," Proceedings of

\section{CONCLUSION}

This paper reports on a scoping review that summarizes the types of experiential learning that have been employed to teach UX to undergraduate and graduate students. We also summarize key student learning outcomes and benefits from participating in EL types. From an initial set of 1,128 articles published from 2000 to retrieved from three databases, we analyzed 45 articles. We found 12 types of experiential learning: applied research project, industry/community research project, hands-on class activity, role-play, interactive workshops, guest speakers, in-house work placement, internship, flipped classroom, field project, lab, and design hackathon, from most to least frequent. We also reported on six student learning outcomes and benefits. We hope that our review serves as a useful source to HCI educators who plan on adopting experiential learning to teach UX.

\section{DATA AVAILABILITY STATEMENT}

The original contributions presented in the study are included in the article/supplementary materials, further inquiries can be directed to the corresponding author.

\section{AUTHOR CONTRIBUTIONS}

JK and NR conducted a scoping review, data analysis, and interpretation. All authors conceptualized and designed the study, contributed to drafting the manuscript, manuscript revision, read, and approved the submitted version.

\section{FUNDING}

This work was supported and funded by the National Sciences and Engineering Research Council of Canada (NSERC) through the Collaborative Learning in Usability Experiences (CLUE) CREATE grant (2015-465639).

the 40th ACM Technical Symposium on Computer Science Education (Chattanooga, TN; New York: ACM Press) 41, 392-396. doi: 10.1145/1539024. 1509003

Byers, K. M., Elsayed-ali, S., Jarjue, E., Kamikubo, R. I. E., Wood, R., Kacorri, H., et al. (2021). "Reflections on remote learning and teaching of inclusive design in HCI," in Proceedings of the 3rd Annual Symposium on HCI Education (EduCHI) (Virtual event), 1-12.

Caine, K. (2016). "Local standards for sample size at CHI," in Proceedings of the CHI Conference on Human Factors in Computing Systems (San Jose, CA), 981-992. doi: $10.1145 / 2858036.2858498$

Chaffin, A., and Barnes, T. (2010). "Lessons from a course on serious games research and prototyping," in Proceedings of the 5th International Conference on the Foundations of Digital Games (New York, NY: ACM Press), 32-39. doi: $10.1145 / 1822348.1822353$

Chi, C. G., and Gursoy, D. (2009). How to help your graduates secure better jobs? An industry perspective. Int. J. Contemp. Hosp. Manag. 21, 308-322. doi: 10.1108/09596110910948314

Christiansson, J., Grönvall, E., and Yndigegn, S. L. (2018). “Teaching participatory design using live projects: critical reflections and lessons learnt," in Proceedings of the 15th Participatory Design Conference (Hasselt; Genk), 1-11. doi: $10.1145 / 3210586.3210597$ 
Churchill, E. F., Bowser, A., and Preece, J. (2013). Teaching and learning human-computer interaction: past, present, and future. Interactions 20, 44 . doi: $10.1145 / 2427076.2427086$

Daun, M., Salmon, A., Weyer, T., and Pohl, K. (2015). “The impact of students' skills and experiences on empirical results: a controlled experiment with undergraduate and graduate students," in ACM International Conference Proceeding Series (Nanjing). doi: 10.1145/2745802.2745829

Edwards, A. D. N., Wright, P., and Petrie, H. (2006). "HCI education: we are failing - why?" in Proceedings of HCI Educators Workshops (Limerick).

El-Glaly, Y., Shi, W., Malachowsky, S., Yu, Q., and Krutz, D. E. (2020). "Presenting and evaluating the impact of experiential learning in computing accessibility education," in Proceedings of the International Conference on Software Engineering (Seoul), 49-60. doi: 10.1145/3377814.33 81710

Getto, G., and Beecher, F. (2016). Toward a model of UX education: training UX designers within the academy. IEEE Trans. Prof. Commun. 59, 153-164. doi: 10.1109/TPC.2016.2561139

Girouard, A., and Kang, J. (2021). "Reducing the UX skill gap through experiential learning : description and initial assessment of collaborative learning of usability experiences program," in Proceedings of the 18th IFIP TC13 International Conference on Human-Computer Interaction (INTERACT2021) (Bari: Springer, Cham), 481-500. doi: 10.1007/978-3-030-85616-8_28

Gittings, L., Taplin, R., and Kerr, R. (2020). Experiential learning activities in university accounting education: a systematic literature review. J. Account. Educ. 52, e100680. doi: 10.1016/j.jaccedu.2020.100680

Gonzalez, C. A., Ghazizadeh, M., and Smith, M. (2014). Perspectives on the training of human factors students for the user experience industry. Proc. Human Factors Ergon. Soc. 58, 1807-1811. doi: 10.1177/15419312145 81378

Gray, C. M., Parsons, P., Toombs, A. L., Rasche, N., and Vorvoreanu, M. (2019). Designing an aesthetic learner experience: UX, instructional design, and design pedagogy. Int. J. Designs Learn. 11, 41-58. doi: 10.14434/ijdl.v11i1.26065

Hamer, L. O. (2000). The additive effects of semistructured classroom activities on student learning: an application of classroom-based experiential learning techniques. J. Market. Educ. 22, 25-34. doi: 10.1177/0273475300221004

Hardy, D., Myers, T., and Sankupellay, M. (2018). "Cohorts and cultures: developing future design thinkers," in Proceedings of the 20th Australasian Computing Education Conference (New York, NY), 9-16. doi: $10.1145 / 3160489.3160494$

Harrison, S. (2005). "Opening the eyes of those who can see to the world of those who can't: a case study," in Proceedings of Technical Symposium on Computer Science Education (St. Louis, MO), 22-26. doi: 10.1145/1047344.1047368

Hassenzahl, M., and Tractinsky, N. (2006). User experience - a research agenda. Behav. Inf. Technol. 25, 91-97. doi: 10.1080/01449290500330331

Hewett, T., Baecker, R., Card, S., Carey, T., Gasen, J., Mantei, M., et al. (1992). ACM SIGCHI Curricula for Human-Computer Interaction. New York, NY: ACM. doi: $10.1145 / 2594128$

Holzer, A., Gillet, D., and Laperrouza, M. (2018). "Active interdisciplinary learning in a design thinking course: going to class for a reason," in Proceeding of the International Conference on Teaching, Assessment, and Learning for Engineering (TALE) (Wollongong, NSW), 906-911. doi: 10.1109/TALE.2018. 8615292

Hui, B. (2020). "Lessons from teaching hci for a diverse student population," in Proceedings of the 20th Koli Calling International Conference on Computing Education Research (Koli), 1-15. doi: 10.1145/3428029.3428054

Kabakova, P., St-Cyr, O., and Furness, C. D. (2021). Monitoring the short-term outcomes of community-engaged, project-based user experience design courses. Int. J. Res. Serv. Learn. Commun. Engag. 8, 18720. doi: $10.37333 / 001$ c. 18720

Kang, J., Trudel, C. M. J., Girouard, A., and Chan, A. D. C. (2021). "Research and education in accessibility, design, and innovation (READi) training program: preparing graduate students for careers in accessibility research and design," in Proceedings of the 3rd Annual Symposium on HCI Education (EduCHI) (Virtual event), 1-8.

Kolb, D. A. (1984). Experiential Learning: Experience as the Source of Learning and Development. Englewood Cliffs, NJ: Prentice Hall.

Konstantinidis, E. I., Petsani, D., and Bamidis, P. D. (2021). Teaching university students co-creation and living lab methodologies through experiential learning activities and preparing them for RRI. Health Inf. J. 27, 1-12. doi: $10.1177 / 1460458221991204$

Koutsabasis, P., and Vosinakis, S. (2012). Rethinking HCI education for design: problem-based learning and virtual worlds at an HCI design studio. Int. J. Human-Comp. Interact. 28, 485-499. doi: 10.1080/10447318.2012.687664

Krusche, S., Dzvonyar, D., Xu, H., and Bruegge, B. (2018). Software theaterteaching demo-oriented prototyping. ACM Trans. Comput. Educ. 18, 1-30. doi: $10.1145 / 3145454$

Lallemand, C. (2021). "Creative pedagogical activities for user evaluation methods courses," in Proceedings of the 3rd Annual Symposium on HCI Education (EduCHI), 1-11. Available online at: https://educhi2021.hcilivingcurriculum. org/wp-content/uploads/2021/04/educhi2021-final76.pdf (accessed July 01, 2021).

Lallemand, C., Gronier, G., and Koenig, V. (2015). User experience: a concept without consensus? Exploring practitioners' perspectives through an international survey. Comp. Human Behav. 43, 35-48. doi: $10.1016 /$ j.chb.2014.10.048

Lazar, J. (2011). "Using community-based service projects to enhance undergraduate HCI education: 10 years of experience," in Proceedings of the Conference on Human Factors in Computing Systems (Vancouver, BC), 581-588. doi: 10.1145/1979742.1979653

Lazem, S. (2019). Championing HCI education to CS undergraduates at a grassroots level: a case study in Egypt. J. Usabil. Stud. 15, 8-22.

Lee, C., Garbett, A., Wang, J., Hu, B., and Jackson, D. (2019). "Weaving the topics of CHI: using citation network analysis to explore emerging trends," in Proceedings of the Conference on Human Factors in Computing Systems (Glasgow), 1-6. doi: 10.1145/3290607.3312776

Leshed, G. (2019). "Scaling student-run workshops in an advanced HCI course," in Proceedings of the 2nd Annual Symposium on HCI Education (EduCHI) (Glasgow), 1-4.

Lima, F. M., da, C., Vasiljevic, G. A. M., De Miranda, L. C., and Baranauskas, M. C. C. (2021). An analysis of IHC and HCII publication titles: revealing and comparing the topics of interest of their communities. J. Inter. Syst. 12, 1-20. doi: 10.5753/jis.2021.997

MacDonald, C. M., and Rozaklis, L. (2017). Assessing the implementation of authentic, client-facing student projects in user experience (UX) education: insights from multiple stakeholders. Proc. Assoc. Inf. Sci. Technol. 54, 268-278. doi: 10.1002/pra2.2017.14505401030

Maher, M., Lou Latulipe, C., Lipford, H., and Rorrer, A. (2015). "Flipped classroom strategies for CS education," in Proceedings of the 46th ACM Technical Symposium on Computer Science Education (Kansas City, MO), 218-223. doi: 10.1145/2676723.2677252

Mohan, S., Chenoweth, S., and Bohner, S. (2012). "Towards a better capstone experience," in Proceedings of the 43rd ACM Technical Symposium on Computer Science Education (Raleigh, NC), 111-116. doi: 10.1145/2157136.2157173

Motschnig, R., Sedlmair, M., Schröder, S., and Möller, T. (2016). "A team-approach to putting learner-centered principles to practice in a large course on HumanComputer Interaction," in Proceedings of the Frontiers in Education Conference (FIE) (Eire, PA), 1-9. doi: 10.1109/FIE.2016.7757576

Musabirov, I., Suvorova, A., Bulygin, D., and Pavel Okopnyi, P. (2019). "Coaligning UX \& development courses: the case of msc in information systems and HCI," in Proceedings of the 2nd Annual Symposium on HCI Education (EduCHI) (Glasgow), 1-7.

Nair, P. R. (2020). Increasing employability of Indian engineering graduates through experiential learning programs and competitive programming: Case study. Proc. Comp. Sci. 172, 831-837. doi: 10.1016/j.procs.2020.05.119

New York Academy of Medicine (2009). What Is Grey Literature? Retrieved from: www.greylit.org/about (accessed September 1, 2022).

Neyem, A., Benedetto, J. I., and Chacon, A. F. (2014). "Improving software engineering education through an empirical approach: lessons learned from capstone teaching experiences," in Proceedings of the 45th ACM Technical Symposium on Computer Science Education (Atlanta, GA), 391-396. doi: $10.1145 / 2538862.2538920$

Patil, M. S., Desai, P., Vijayalakshmi, M., Raikar, M. M., Battur, S., Parikshit, H., et al. (2016). "UX design to promote undergraduate projects to products: case study," in Proceedings of the 4th International Conference on MOOCs, Innovation and Technology in Education (MITE), 302-307. doi: 10.1109/MITE.2016.066 
Patricia, L. (2011). "Service learning: An HCI experiment," in Proceedings of the 16th Western Canadian Conference on Computing Education, 12-16. doi: $10.1145 / 1989622.1989626$

Péraire, C. (2019). "Dual-track agile in software engineering education," in Proceedings of the 41st International Conference on Software Engineering: Software Engineering Education and Training (Montreal, QC), 38-49. doi: 10.1109/ICSE-SEET.2019.00013

Poor, G. M., Leventhal, L. M., Barnes, J., Hutchings, D. R., Albee, P., and Campbell, L. (2012). No user left behind: including accessibility in student projects and the impact on CS students' attitudes. ACM Trans. Comput. Educ. 12, 1-22. doi: $10.1145 / 2160547.2160548$

PRISMA (2021). PRISMA for Scoping Reviews. Available online at: http://www. prisma-statement.org/Extensions/ScopingReviews (accessed June 01, 2021).

Radermacher, A., and Walia, G. (2013). "Gaps between industry expectations and the abilities of graduates," in Proceedings of the 44th ACM Technical Symposium on Computer Science Education (Denver, CO), 525-530. doi: 10.1145/2445196. 2445351

Robinson, S., and Hall, M. (2018). "Combining agile software development and service-learning: a case study in experiential IS education," in Proceedings of the 49th ACM Technical Symposium on Computer Science Education (Baltimore, MD), 491-496. doi: 10.1145/3159450.3159564

Roldan, W., Gao, X., Hishikawa, A. M., Ku, T., Li, Z., Zhang, E., et al. (2020). "Opportunities and challenges in involving users in project-based HCI education," in Proceedings of the Conference on Human Factors in Computing Systems (Honolulu, HI), 1-15. doi: 10.1145/3313831.3376530

Roldan, W., Li, Z., Gao, X., Kay Strickler, S., Marie Hishikawa, A., E., et al. (2021). "Pedagogical strategies for reflection in project-based HCI education with end users," in Proceedings of the Designing Interactive Systems Conference (Honolulu, HI), 1846-1860. doi: 10.1145/3461778.3462113

Rosala, M., and Krause, R. (2019). User Experience Careers What a Career in UX Looks Like Today. Nielsen Norman Group. Available online at: https://www. nngroup.com/reports/user-experience-careers (accessed June 01, 2021).

Sánchez, A., Domínguez, C., Blanco, J. M., and Jaime, A. (2019). Incorporating computing professionals' know-how: differences between assessment by students, academics, and professional experts. ACM Trans. Comp. Educ. 19, 3309157. doi: 10.1145/3309157

Santana-Mancilla, P. C., Rodriguez-Ortiz, M. A., Garcia-Ruiz, M. A., Gaytan-Lugo, L. S., Fajardo-Flores, S. B., and Contreras-Castillo, J. (2019). Teaching HCI skills in higher education through game design: a study of students' perceptions. Informatics 6, 22. doi: 10.3390/informatics6020022

Santoso, H. B., and Sari, E. (2015). "Transforming undergraduate HCI course in Indonesia: a preliminary study," in Proceedings of the Asia Pacific HCI and UX Design Symposium (Melbourne, VIC), 55-59. doi: 10.1145/2846439.2846451

Satterfield, D., and Fabri, M. (2017). "User Participatory Methods for Inclusive Design and Research in Autism: A Case Study in Teaching UX Design," in Design, User Experience, and Usability: Theory, Methodology, and Management, eds A. Marcus and W. Wang (Berlin: Springer), 186-197. doi: 10.1007/978-3-319-58634-2_15

Scherer, R. W., and Saldanha, I. J. (2019). How should systematic reviewers handle conference abstracts? A view from the trenches. Syst. Rev. 8, 264. doi: 10.1186/s13643-019-1188-0

Scott, M. J., Parker, A., McDonald, B., Lewis, G., and Powley, E. J. (2019). "Nurturing collaboration in an undergraduate computing course with robot-themed team training and team building," in Proceedings of the 3rd Conference on Computing Education Practice (Durham), 1-4. doi: 10.1145/3294016.3294019

Shalamova, N. (2016). "Blending engineering content with design thinking and UX to maximize student engagement in a technical communication class," in Proceedings of the International Professional Communication Conference (Austin, TX), 1-5. doi: 10.1109/IPCC.2016.7740493

Shinge, J., Kotabagi, S. V., Geeta, M., Rebello, C., Sujatha, N. M., and Anusha, K. (2021). Transforming young minds socially through, a course social innovation with a human centred design approach at freshman level of engineering. J. Eng. Educ. Trans. 34, 557-565. doi: 10.16920/jeet/2021/v34i0/157213

Shinohara, K., Bennett, C. L., and Wobbrock, J. O. (2016). "How designing for people with and without disabilities shapes student design thinking," in Proceedings of the 18th International ACM SIGACCESS Conference on Computers and Accessibility (Reno, NV), 229-237. doi: $10.1145 / 2982142.2982158$
Solano, A. (2017). "Teaching experience of the human-computer interaction course at the Universidad AutóNoma de Occidente of Colombia," in Proceedings of the XVIII International Conference on Human Computer Interaction (Cancun), 1-2. doi: 10.1145/3123818.3123822

Sucharew, H., and Macaluso, M. (2019). Methods for research evidence synthesis: the scoping review approach. J. Hosp. Med. 14, 3248. doi: 10.12788/jhm.3248

Talone, A. B., Basavaraj, P., and Wisniewski, P. J. (2017). "Enhancing humancomputer interaction and user experience education through a hybrid approach to experiential learning," in Proceedings of the 18th Annual Conference on Information Technology Education (Rochester, NY), 83-88. doi: $10.1145 / 3125659.3125685$

Tiwalolu (2018). User Experience Branches. Available online at: https://medium. com/nyc-design/user-experience-branches-eea9389fadd6 (accessed June 01, 2021).

usability.gov (n.d.). User Experience Basics. Retrieved from: https://www.usability. gov/what-and-why/user-experience.html (accessed July 19, 2021).

Veritas Health Information (2014). Covidence [Systematic review software]. Retrieved from: www.covidence.org.

Vorvoreanu, M., Gray, C. M., Parsons, P., and Rasche, N. (2017). "Advancing UX education: a model for integrated studio pedagogy," in Proceedings of the Conference on Human Factors in Computing Systems (Denver, CO), 1441-1446. doi: $10.1145 / 3025453.3025726$

Waller, A., Hanson, V. L., and Sloan, D. (2009). "Including accessibility within and beyond undergraduate computing courses," in Proceedings of the 11th International ACM SIGACCESS Conference on Computers and Accessibility (Pittsburgh, PA), 155-162. doi: 10.1145/1639642. 1639670

Wang, Y. D. (2012). "A holistic and pragmatic approach to teaching web accessibility in an undergraduate web design course," in Proceedings of the ACM Special Interest Group for Information Technology Education Conference (Calgary, AB), 55-60. doi: 10.1145/2380552.2380568

Wei, X., Saab, N., and Admiraal, W. (2021). Assessment of cognitive, behavioral, and affective learning outcomes in massive open online courses: a systematic literature review. Comp. Educ. 163, 104097. doi: 10.1016/j.compedu.2020.104097

Xin, X., Liu, W., and Wu, M. (2018). "Reflecting on industrial partnered and project based master course of 'UX Foundation' BT - design, user experience, and usability: designing interactions," in Proceedings of the International Conference of Design, User Experience, and Usability, eds A. Marcus and W. Wang (Las Vegas, NV: Springer International Publishing), 148-157. doi: 10.1007/978-3-319-91803-7_11

Yargin, G., Süner, S., and Günay, A. (2018). "Modelling user experience: integrating user experience research into design education," in Proceedings of the International Conferences on Interfaces and Human Computer Interaction (Madrid), 26-34.

Zhao, Q., Mande, V., Conn, P., Al-Khazraji, S., Shinohara, K., Ludi, S., et al. (2020). "Comparison of methods for teaching accessibility in university computing courses," in Proceedings of the 22nd International ACM SIGACCESS Conference on Computers and Accessibility (Virtual event), 1-12. doi: $10.1145 / 3373625.3417013$

Conflict of Interest: The authors declare that the research was conducted in the absence of any commercial or financial relationships that could be construed as a potential conflict of interest.

Publisher's Note: All claims expressed in this article are solely those of the authors and do not necessarily represent those of their affiliated organizations, or those of the publisher, the editors and the reviewers. Any product that may be evaluated in this article, or claim that may be made by its manufacturer, is not guaranteed or endorsed by the publisher.

Copyright (๑) 2022 Kang, Roestel and Girouard. This is an open-access article distributed under the terms of the Creative Commons Attribution License (CC BY). The use, distribution or reproduction in other forums is permitted, provided the original author(s) and the copyright owner(s) are credited and that the original publication in this journal is cited, in accordance with accepted academic practice. No use, distribution or reproduction is permitted which does not comply with these terms. 